\title{
El campo conceptual de la 'claridad' en el discurso hablado desde un enfoque cognitivo en la fraseología bilingüe (alemán-español)
}

\author{
Ana MansiLla PÉREZ \\ Universidad de Murcia \\ anamansi@um.es
}

Recibido: 13 de octubre de 2013

Aceptado: 18 de noviembre de 2013

\section{RESUMEN}

El presente trabajo aborda la conexión existente entre el campo conceptual de la 'claridad' del discurso hablado y tres esquemas de imágenes: CENTRO-PERIFERIA, RECIPIENTE y CAMINO. La perspectiva utilizada se encuadra en la semántica cognitiva, centrándonos fundamentalmente en el análisis de tres metáforas LA CLARIDAD ESTÁ EN EL CENTRO, LA CLARIDAD ES UN MOVIMIENTO DE DENTRO A FUERA y LA CLARIDAD ES UN CAMINO RECTO Y LISO. De la mano del corpus onomasiológico bilingüe FRASESPAL, el análisis contrastivo de más de 120 unidades fraseológicas constata paralelismos y correspondencias existentes en ambas fraseologías, que confirma que los sistemas lingüísticos y fraseológicos del alemán y el español conceptualizan el mundo extralingüístico de manera similar en torno a metáforas coincidentes.

Palabras clave: Fraseología contrastiva, claridad, español, alemán.

\section{The Conceptual Field of 'Clarity' in Spoken Discourse from a Cognitive} Focus on Bilingual (German-Spanish) Phraseology

\begin{abstract}
This paper explores the connection between the conceptual field of 'clarity' in spoken discourse and the three image schemata: CENTRE-PERIPHERY, CONTAINER and PATH. The perspective employed is cognitive semantics, with a focus on the analysis of three metaphors: CLARITY IS CENTRAL, CLARITY IS MOVEMENT FROM INSIDE TO OUTSIDE and CLARITY IS A STRAIGHT AND EVEN PATH. With the aid of the bilingual onomasiological corpus FRASESPAL, the contrastive analysis of over 120 phraseological units reveals parallelisms and correspondences in both phraseologies, confirming that the language and phraseological systems of German and Spanish offer similar conceptualizations of the extralinguistic world by means of metaphors that largely coincide.
\end{abstract}

Keywords: Contrastive Phraseology, Clarity, Spanish, German. 
SUMARIO: 1. Introducción. 2. Esquema de imagen CENTRO-PERIFERIA. 2.1. La metáfora LA CLARIDAD ESTÁ EN EL CENTRO / LA FALTA DE CLARIDAD ESTÁ EN LA PERIFERIA. 3. Esquema de imagen RECIPIENTE. 3.1. La metáfora LA CLARIDAD ES APERTURA. 4. Esquema de imagen CAMINO. 4.1. La metáfora LA CLARIDAD ES UN CAMINO RECTO Y LISO. 5. Conclusiones.

\section{Introducción}

Tomando como punto de referencia los postulados que dicta la lingüística cognitiva, nuestra experiencia cotidiana está corporeizada y, por ende, íntimamente ligada a la estructura de nuestro cuerpo (experiencia corpórea, física y social). Lakoff (1987) distingue cuatro formas de subdividir el conocimiento: la organización proposicional, las proyecciones metafóricas, las proyecciones metonímicas, y la esquematización de imágenes. Estas cuatro entidades conceptuales se denominan "modelos cognitivos idealizados".

Para nuestro estudio vamos a poner el punto de mira en la cuarta entidad conceptual arriba señalada: la esquematización de imágenes. Los esquemas de imágenes que conforman junto con las metáforas cognitivas el fundamento sobre el cual el ser humano conceptualiza la realidad circundante (Roos 2001: 122), son representaciones cognitivas de hechos, percepciones, relaciones u objetos y constituyen una forma de experiencia elemental preconceptual. Según los postulados de Lakoff y Johnson (1986), el sistema conceptual humano está corporeizado y por medio de este se desarrollan patrones o esquemas en interactuación con nuestra experiencia. En este sentido, los esquemas de imágenes facilitan la conceptualización de lo psíquico (sentimientos y sensaciones), ya que se basan principalmente en la manipulación de objetos, en movimientos corporales y en interacciones perceptuales (Montoro del Arco 2007: 131). Entre los esquemas de imágenes que Lakoff y Johnson (1986) proponen, citamos los siguientes: RECIPIENTE, COACCIÓN, CAPACITACIÓN, ATRACCIÓN, VÍNCULO, CENTRO-PERIFERIA, PARTE-TODO, CICLO, SUPERFICIE, PROCESO.

Cuando hablamos, recorremos un espacio en un tiempo determinado, siendo la forma que presenta la trayectoria (CAMINO) determinante para la calidad del discurso emitido, por ejemplo, hablar de forma directa o hablar con rodeos. Por otra parte, la noción de expresar ideas es comprensible fundamentalmente en el contexto del esquema de imagen del RECIPIENTE, por el hecho de que cuando emitimos un enunciado se vierten hacia el exterior las ideas contenidas en el recipiente. Asimismo, las ideas conforman una estructura ligada a nuestra experiencia corporeizada (tronco y extremidades) que en el caso que nos ocupa se traduce en términos de CENTRO o PERIFERIA (ideas centrales y relevantes frente a ideas periféricas o secundarias).

\footnotetext{
${ }^{1}$ Se denomina "modelo cognitivo idealizado" porque tiene que ver con el hecho de que los conceptos cognitivos no están presentes en la naturaleza, más bien en el pensamiento humano.
} 
Así pues, nuestro estudio tiene por objeto, a partir de los datos extraídos del corpus onomasiológico bilingüe FRASESPAL ${ }^{2}$, constatar cómo diferentes conceptos como el espacio (camino), el movimiento (de dentro a afuera) y la estructura (centro y periferia), y que entre otros derivan de tres metáforas UNA ARGUMENTACIÓN ES UN VIAJE, UNA ARGUMENTACIÓN ES UN RECIPIENTE y UNA ARGUMENTACIÓN ES UN EDIFICIO, tienen cabida en el campo conceptual de la 'claridad' en el discurso hablado en algunas expresiones fraseológicas del español y del alemán. Lo interesante de este trabajo es explorar y detectar cómo los distintos esquemas de imágenes se plasman en alemán y en español de modo prácticamente similar.

\section{Esquema de imagen CENTRO-PERIFERIA}

\subsection{La metáfora LA CLARIDAD ESTÁ EN EL CENTRO / LA FALTA DE CLARIDAD ESTÁ EN LA PERIFERIA}

Mark Johnson define el esquema CENTRO-PERIFERIA en los siguientes términos:

El punto central representa mi centro perceptivo y empírico, centro que define mi espacio empírico y que desaparece progresivamente en mi horizonte (línea ondulada). De momento nos hemos referido al esquema de CENTRO-PERIFERIA como si sólo fuera cuestión de mi espacio empírico. Algunas cosas, acontecimientos y personas de mi "universo" son más importantes que otras: destacan más en mi experiencia y son más centrales para mis interacciones. Otras son relativamente periféricas en determinado punto del tiempo. [...] De una manera aún más abstracta podemos decir que la totalidad de nuestra comprensión presenta un contorno de horizonte (1991: 201).

Esta cita nos ayuda a entender de qué modo el ser humano conceptualiza la realidad circundante. Tomamos como punto de referencia nuestro propio cuerpo, el cual constituye el centro desde el que vemos, oímos o tocamos el mundo que nos circunda. Sirviéndonos de las palabras de Johnson, este centro conforma nuestro "espacio empírico" que percibimos de forma más relevante que otros espacios que se desmarcan de dicho centro. Por consiguiente, todo lo que se distancia del cuerpo como CENTRO, se ve difuminado y deja de ser sustancial. Si pensamos en las partes vitales del cuerpo humano (tronco, órganos viscerales como hígado, pulmones, corazón, riñón), éstas se ubican en el centro, por lo que desempeñan una función

${ }^{2}$ El proyecto FRASESPAL ha llevado a cabo la elaboración de un tesauro bilingüe alemán-español de ordenación onomasiológica y de acuerdo con una metodología inductiva. El marco teórico se circunscribe a la semántica cognitiva de LAKOFF / JOHNSON (1986) y LAKOFF (1989) y a la teoría de la modelación de BARANOV / DOBROVOL' SKIJ (1991). Los campos conceptuales que hemos analizado (HABLAR/CALLAR, VIDA/MUERTE y SALUD/ENFERMEDAD) engloban UF (unidades fraseológicas) de semántica más o menos prototípica en relación con el taxón o modelo cognitivo en el que se agrupan. 
esencial en el cuerpo humano y se proyectan en las emociones y facultades intelectuales del hombre (Luque Durán 2004: 513). Por ello, este esquema que responde a dos metáforas CENTRO ES POSITIVO y PERIFERIA ES NEGATIVO y LO IMPORTANTE ES CENTRAL y LO ACCESORIO ES PERIFÉRICO (Jäkel 2003: 158), tiene proyecciones metafóricas en los acontecimientos, cosas o intereses de la vida misma, es decir, determinados hechos son centrales y dan origen a numerosas UF, esp. el meollo de la cuestión, el ombligo del mundo, hablar de todo corazón; al. alles frisch von der Leber weg reden, mit Hand aufs Herz, sich für den Nabel der Welt halten, etc. (Mellado Blanco 1999: 337).

Los órganos vitales y, por tanto, céntricos, como el corazón, el hígado o sustancias como la médula, se proyectan hacia conceptos como la verdad, la sinceridad, la esencia o la profundidad de un asunto. Por ejemplo, el corazón evidencia en ambas fraseologías de forma manifiesta la sinceridad. Así pues, esp. de todo corazón, con el corazón en la mano, salirle del corazón, irse la boca a donde está el corazón; al. Hand aufs Herz; aus tiefstem/vollem Herzen; sich etw. vom Herzen reden; jmdm. sein Herz ausschütten, etw. vom Herzen kommen, etc. Estas UF parten del esquema de imagen CENTRO-PERIFERIA (Johnson 1987: 124-25), que se apoya en la metáfora EL CORAZÓN ES EL NÚCLEO O CENTRO DE ALGO. Olza Moreno hace alusión al respecto en los siguientes términos:

En estas expresiones suele intervenir, además, el esquema de imagen CENTROPERIFERIA (Johnson 1987, 124-125), por el que los órganos situados en el centro del cuerpo humano - proverbialmente, el corazón- son los responsables de un discurso auténtico, sincero, conectado con las verdaderas emociones del sujeto, mientras que la falta de concordancia entre pensamiento, sentimiento y discurso se asocia a las palabras que provienen de órganos periféricos, sobre todo, la boca -en español: de boca para afuera, [ser u. c.] de boca y de boquilla-y los labios - de labios afuera, du bout des lèvres- (2006: 169).

La UF con el corazón en la mano / Hand aufs Herz es un tipo de UF textual transparente y codifica el gesto real de llevarse la mano al corazón como garantía de sinceridad. Por lo que respecta al uso de estas UF en su contexto, se observan divergencias en ambas lenguas. A diferencia de la UF alemana Hand aufs Herz, la UF española se emplea con verbos del decir, en la que el emisor expresa una actitud ('ser sincero') respecto a la acción verbal: Te lo digo con el corazón en la mano. En cambio en la UF alemana se pone de manifiesto el nexo existente entre los interlocutores: Jetzt mal, Hand aufs Herz (con frecuencia en combinación con oraciones de imperativo en singular $)^{3}$.

Desde un punto de vista metafórico, la claridad del mensaje emitido es CENTRAL y subyace al esquema de orientación CENTRO-PERIFERIA, y lo podemos observar a través de las siguientes UF: esp. ir (directamente) al grano, ir al meollo, ir al tuétano, centrarse en un punto, ir al quid de la cuestión, dejarse de rodeos, etc.;

${ }^{3}$ Es importante no confundir la UF Hand aufs Herz con la UF mit Herz und Hand que connota decisión y convencimiento: "Stehen wir mit Herz und Hand für die Verteidigung dieses Staates ein". 
al. zum Kern der Sache vordringen/kommen, den Kern des Problems/der Sache treffen, einen wahren Kern haben, der Kernpunkt der Rede, das ist gerade der Punkt, ein Körnchen Wahrheit steckt in etwas, etw. auf den Punkt bringen, auf den Punkt kommen, etc. En clara conexión con la unidad léxica médula, la UF ir al meollo que proviene del lat. vulg. medullum, y este a su vez del lat. medulla, subyace a la metáfora cognitiva HABLAR DE FORMA CONCISA ES CONCENTRARSE EN UN PUNTO (Herrero Kaczmarek 2011: 182). Este hecho deja translucir que la claridad va pareja a la brevedad (de corta duración o extensión) y, por ende, la falta de claridad es expansión (temporal y espacial). Curiosamente, existe en la fraseología alemana la tendencia a identificar metafóricamente los lexemas Knochenmark [esp. tuétano] y Mark [esp. meollo, médula] con la profundidad, o intensidad de un hecho: bis ins Mark durchkältet sein, bis ins Mark frösteln, jdn. bis ins Mark treffen, etc., desmarcándose aquellos tenuemente del campo conceptual 'hablar con claridad'. Un equivalente fraseológico en español lo conforman las UF estar enamorado hasta la médula, ser español/corrupto/... hasta la médula, etc.

En sus orígenes, circunscrito al ámbito de la agricultura, la UF ir al grano hace referencia, además de 'ser claro', al hecho de acertar o dar con la solución de un problema. Equivalentes funcionales alemanes de la UF ir al grano lo constituyen las UF auf den Punkt kommen, zum Kernpunkt kommen, den Kern des Problems treffen, bis zum Kern eines Problems/... vordringen, der Kernpunkt seiner Rede, einen wahren Kern haben, etc.

\section{Esquema de imagen RECIPIENTE}

La imagen del RECIPIENTE es muy recurrente desde un punto de vista fraseológico tanto en el campo de los pensamientos o recuerdos como en el campo de los sentimientos. Según Baldauf (1997: 130) el ser humano se concibe como un espacio en forma de contenedor o recipiente que comprende sentimientos y objetos que pueden o no moverse y que ejercen una influencia en la forma del recipiente. Dentro del cuerpo humano es el corazón el órgano con más representatividad para designar metafóricamente CLARIDAD a partir del esquema de imagen del RECIPIENTE. El corazón como RECIPIENTE (Roos 2001: 210) se abre para expresar preocupación o culpa, estos sentimientos pueden forzar al hablante a desahogarse con su interlocutor. Muestra de ellos son las UF abrirle su corazón a alg., abrirle su pecho a alg.; al. jdm. sein Herz öffnen. Estas UF activan, asimismo, la metáfora LA CLARIDAD ES APERTURA, LA FALTA DE CLARIDAD ES CIERRE. La imagen del RECIPIENTE (Lakoff/Johnson 1986: 67) engloba, a su vez, las imágenes ABIERTO/CERRADO.

Johnson (1987: 42) asocia la imagen de la APERTURA al esquema RECIPIEN$\mathrm{TE}$, que se traduce en que un agente que es víctima de una fuerza opresiva, se logra deshacer de esta cuando se desahoga. Cuando la presión interna dentro del recipiente es muy alta, provocada por el exceso de emoción, el recipiente explota. De ahí podemos inferir fácilmente la realización metafórica LA EMOCIÓN ES UN FLUIDO EN UN RECIPIENTE (Ungerer y Schmid 1996: 140). Un nutrido con- 
junto de unidades fraseológicas en alemán se apoya en la metáfora LA SINCERIDAD ES UN MOVIMIENTO DE DENTRO A FUERA: $j d m$. sein Herz ausschütten, $j d m$. aus dem Herzen sprechen, seinem Herzen Luft machen. En el caso concreto de la UF jdm. sein Herz ausschütten [tr. lit. 'verter su corazón a alg.'], se conceptualiza la imagen de la opresión a la que está sometido el corazón como RECIPIENTE, cuya excesiva carga (emotiva) debe de ser liberada, y así evitar que se derrame. Hemos encontrado en la fraseología española una metáfora similar con la idea del vertido de algo interior que oprime: verter/derramar alg. sus preocupaciones en algo/alg.

Sabine Geck (2003: 203) sostiene que la ubicación exacta de las emociones dentro del cuerpo lo conforman las vísceras, órganos que atañen directamente a estados emocionales contrapuestos a la razón. Las vísceras están ligadas a la espontaneidad o falta de meditación, es decir, 'hablar con sinceridad' conlleva no pocas veces la ausencia de prudencia o de lógica. De todo ello se desprende la metáfora local LAS EMOCIONES ESTÁN EN LAS VÍSCERAS. De forma general, se aprecia una dicotomía: la cabeza y el tronco, y dentro de este, los diferentes órganos ubicados en el mismo: esp. corazón, pecho, hígado, testículos; al. Herz, Brust, Magen, Leber, Eier, etc. Cabe decir que el componente léxico 'hígado' en alemán posee el significado fraseológico de 'franqueza' y de 'sinceridad' en las UF frisch/frei von der Leber weg reden y sich etwas von der Leber reden, un significado traslaticio que no hemos detectado en la fraseología española. La palabra 'hígado', de una parte, representa un ánimo caracterizado por la decisión, la capacidad de esfuerzo y la perseverancia, entre otros. De otra, el hígado 4 es la sede de las emociones, de las pasiones y de los deseos. Otra UF alemana que connota 'sinceridad' se asocia al componente Seele en sich die Seele aus dem Leib reden y tiene que ver con el hecho de desahogarse, descargar una pena o preocupación en alguien.

Las UF salirle del alma algo a alg. o salirle del corazón algo a alg., son prototípicos del concepto 'sinceridad'. Las ideas ejercen una fuerza desde dentro del recipiente hacia fuera. La sinceridad puede a su vez ir cogida de la mano de la falta de control o desinhibición, que se constata en las UF alemanas aus sich herausgehen, frei heraus etw. sagen o mit der Sprache herausrücken. En conexión con la falta de control, llama la atención que la línea que separa la sinceridad de la agresión verbal sea muy tenue, como se aprecia en las siguientes UF: esp. no tener pelos en la lengua, soltarle algo a alg. a la cara, soltar la lengua, etc.; al. jdm. etw. offen ins Gesicht sagen, jdm. reinen Wein einschenken, jdm. die ungeschminkte Wahrheit sagen. Estos ejemplos se relacionan, en función del contexto, tanto con el concepto de la 'sinceridad', como con la 'agresión verbal' (reprimenda, crítica, injuria). A este

${ }^{4}$ En este punto cabe recordar la influencia del médico Hipócrates en referencia a los cuatro humores fundamentales que fluyen a través del cuerpo: la sangre, la flema, la bilis amarilla y la bilis negra. Estos, a su vez, equivalían a los cuatro elementos que constituían el universo: sanguíneo (aire-sangre), flemático (agua-flema o pituita), bilioso (fuego-bilis amarilla) o melancólico (tierra-bilis negra o atrabilis). La desproporción de alguno de los cuatro elementos conduce a diversos desequilibrios mentales o temperamentales. Si bien esta teoría hipocrática puede resultar hoy anacrónica, ha perdurado en el lenguaje. 
respecto Santos y Espinosa (1996) argumentan una serie de metáforas fundamentales que están presentes en todas las emociones: EL CUERPO ES UN RECIPIENTE DE LAS EMOCIONES y LAS EMOCIONES SON FLUIDOS CONTENIDOS EN EL CUERPO.

\subsection{La metáfora LA CLARIDAD ES APERTURA}

La claridad supone APERTURA, ausencia de obstáculos, límites o barreras (Aznárez Mauleón 2006: 300). Lo que está dentro del recipiente oculto es necesario sacarlo al exterior y exponerlo, porque es una forma de liberar un espacio: esp. hablar sin cortapisas, hablar abiertamente, hablar sin reservas, no tener frenillo en la lengua; al. offen reden, ungehemmt reden, kein Blatt vor den Mund nehmen, aus etw. keinen Hehl machen, frank und frei reden, frei und offen reden. Estas UF subyacen a la metáfora LA CLARIDAD ES AUSENCIA DE LÍMITES o LA CLARIDAD ES LIBERTAD.

La APERTURA va cogida de la mano de la desnudez que simboliza la pureza, es decir, la ausencia de pecado, (Rigotti 1993: 244): esp. al desnudo, a calzón quitado, a pecho descubierto; al. die nackte Wirklichkeit, etw. mit nackten Worten sagen. En la mayoría de los testimonios encontrados, la UF a calzón quitado está emparentada con una forma de hablar que denota ausencia de vergüenza. Habitualmente se asocia el uso de esta UF a abordar de forma clara temas espinosos como la sexualidad o la política, entre otros, además de hacer referencia a un tipo de formulación clara y directa que se construye discursivamente desde el punto de vista de su correspondencia con la realidad (Robles i Sabater 2005: 58). La UF frei/frisch von der Leber (weg) sprechen constituye el equivalente funcional de la UF a calzón quitado, que ilustramos con el siguiente ejemplo:

Pero, ¿cómo ser mujer? Esa es precisamente la gran, eterna pregunta a la que Caitlin Moran se propone responder en una obra que aborda a calzón quitado - a veces literalmente-, con inteligencia, desvergüenza e ironía y también una salvaje franqueza, los principales aspectos de la condición femenina ${ }^{5}$.

La UF [verbo] sin tapujos designa discursos diáfanos, claros, es decir, sin disfraz. Los verbos de lengua que acompañan a esta UF prepositiva, son, entre otros, 'escribir', 'hablar', 'expresarse', 'declarar', etc. En estrecha relación con el concepto APERTURA, constatamos la metáfora DESVELAR ES DESTAPAR. Muestra de ello es la unidad léxica 'velo' que se emplea en ambas fraseologías con un significado sinónimo: esp. correr un velo; al. den Schleier lüften, den Schleier von etw. reißen. En las UF alemanas, la primera de ellas se proyecta hacia el hecho de revelar un secreto, en cambio, la segunda UF está directamente relacionada con la UF die Maske fallen lassen. Es interesante observar que el verbo alemán lüften encierra otra metáfora cognitiva que entronca indirectamente con la suciedad: LA MENTIRA ES SUCIEDAD, y por contraposición LA VERDAD ES PUREZA. Así, pues:

\footnotetext{
${ }^{5}$ [GOOGLE: http://www.anagrama-ed.es/titulo/PN_840].
} 
esp. hablar claro, en puridad, la pura verdad; al. jdm. reinen Wein einschenken, die reine Wahrheit sagen, etw. ins Reine bringen. En la fraseología española la UF hablar sin rebozo constituye el ejemplo que mejor encarna el concepto DESTAPAR, con ausencia de equivalente fraseológico en alemán. Según Aznárez Monleón (2006: 315), la principal razón que se aduce para utilizar rebozos (capa o el modo de llevarla para cubrir el rostro) en el habla es el temor a que la imagen del hablante se vea dañada y, por tanto, a las consecuencias posteriores.

En otro orden de cosas, la metáfora del libro abierto se relaciona con una comunicación abierta, y, por ende, sincera. Lo constituyen las UF ser un libro abierto, ein offenes Buch sein. Si bien en español la UF puede hacer referencia a la transparencia y a la elocuencia, en alemán la UF va pareja a la franqueza y claridad. Las UF hablar como un libro (abierto) y reden wie ein Buch únicamente comparten el significado fraseológico de la elocuencia. En alemán se registra otro significado que no está contenido en la UF española, se trata de la profusión en el discurso hablado. Por lo cual se trata de falsos amigos parciales.

En conexión con la imagen de destapar el rostro o la cara, detectamos la UF mit offenem Visier kämpfen, cuya unidad léxica 'visera' no encuentra correlato en la fraseología española. En este sentido, observamos el equivalente fraseológico actuar a cara descubierta. La UF mit offenem Visier kämpfen gravita sobre el núcleo verbal kämpfen y no es más que una realización específica de la metáfora universal ARGUMENTATION IS WAR, en la que las discusiones verbales se conceptualizan en términos bélicos. El siguiente ejemplo lexicográfico nos ilustra esta afirmación:

Aber es ist doch sinnlos, nach außen so zu tun, als ob er mit uns übereinstimmt, und uns hintenherum zu bekämpfen! - Der Peter sagt nie offen, was er denkt, kämpft nie mit offenem Visier, daran mußt du dich gewöhnen. (Schemann et al. 2013: 1068).

\section{El esquema de imagen CAMINO}

\subsection{La metáfora LA CLARIDAD ES UN CAMINO RECTO Y LISO}

La relación entre metáfora y camino ha sido ya ampliamente abordada desde una perspectiva cognitiva, especialmente por George Lakoff y su colaborador Mark Johnson (Lakoff 1989; Johnson 1991). De este estudio, son relevantes dos esquemas de imagen, a saber, RECIPIENTE y CAMINO. Este último se vincula a la noción de movimiento y a la trayectoria. Esclarecedora en este sentido resulta la afirmación de Johnson (1987: 38):

When we reason, we understand ourselves as starting at some point (a proposition or set of premises), from which we proceed in a series of steps to a conclusion (a goal, or stopping point). Metaphorically, we understand the process of reasoning as a form of motion along a path - propositions are the locations (or bounded areas) that we start out from, proceed through, and wind up at. Holding a proposition is understood metaphorically as being located at that point (or in that area). This very general metaphorical system is reflected in our language about reasoning in a large number of ways. 


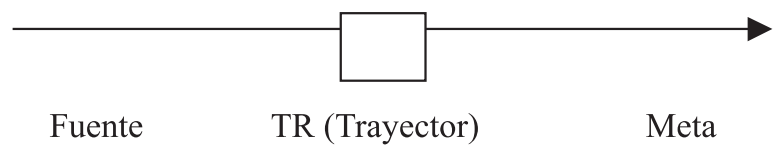

La comunicación es un objeto (entendido también como proceso) que avanza. Si el objeto sigue una trayectoria clara, la comunicación está controlada. Desviarse del camino, retroceder o atajar en el camino implicaría que la comunicación está fuera de control lo cual conlleva una merma en la claridad discursiva. UF tales como desviarse del tema, atajar en un asunto, rodear un tema, ir directo a un asunto/a un tema, etc. activan de manera automática el esquema de imagen CAMINO.

El concepto RECTO se circunscribe fundamentalmente a la correlación que existe entre la forma de un objeto y su comportamiento y encuentra su motivación en la metáfora primaria LA CONDICIÓN ES FORMA y LO NORMAL ES RECTO. Esta última se desprende de la experiencia perceptiva de considerar la simetría o regularidad de las formas como hechos normales, y, por oposición, de tratar las irregularidades como anomalías. En el ámbito de la 'claridad' en el discurso hablado, las UF sin rodeos, ohne Umwege subyacen a la metáfora cognitiva LA CLARIDAD ES BREVEDAD, y LA FALTA DE CLARIDAD ES UN MOVIMIENTO CIRCULAR. Estas, a su vez, son realizaciones lingüísticas de la metáfora LAS IDEAS SON MOVIMIENTOS y UN PENSAMIENTO EFICIENTE ES UN MOVIMIENTO DIRECTO. La 'rectitud' refleja en español la distancia más breve entre dos puntos o términos y en el ámbito de la moral hace referencia (s. v. rectitud) en su cuarta acepción en el DRAE al siguiente significado: 4. "Recta razón o conocimiento práctico de lo que debemos hacer o decir". Si bien la UF hablar con rectitud se refiere a una forma de hablar sincera, además de correcta, va asociada fundamentalmente a los verbos 'comportarse' o 'actuar'. En contraposición al concepto RECTO, los calificativos 'torcido' y su equivalente alemán krumm nos proporcionan connotaciones negativas desde un punto de vista de la falta de moral, de legalidad, o la modificación de un plan, tema, entre otros (Mansilla 2013: 340). Así pues, al. auf krummen Pfaden wandeln, krumme Geschäfte, krumme Wege gehen, etw. gerät in ein schiefes Licht; esp. torcer los planes, torcer el curso/los planes de algo, tergiversar [un asunto], una realidad torcida, etc.

Siguiendo en la misma línea, la metáfora subyacente de la UF sin ambages ${ }^{6}$ es HABLAR CLARO ES UN MOVIMIENTO RECTO, la cual encuentra correspondencia en la fraseología alemana por medio de las UF gerade Wege gehen o gerade heraus [sagen]. La UF ir por el camino recto está enmarcada en el ámbito de la moral y la ética, al igual que se procede en la fraseología alemana con la UF ein gerader Mensch ('una persona recta'). La UF sin circunloquios que subyace a la metáfora LA CLARIDAD ES BREVEDAD, supone un ejemplo de UF metalin-

${ }^{6}$ La unidad léxica ambages procede del latín, que consta de un prefijo amb- ('por un lado y por otro') sobre la raíz del verbo agere ('impulsar hacia delante'). 
güística con correlato en alemán en la UF ohne Umschweife, la cual alude a la unidad léxica Schweif y que se vincula a la parte final de una prenda de vestir en forma de cola, esto es, en forma circular. La UF sin circunloquios se emplea con frecuencia en contextos que evidencian un lenguaje claro carente de artificiosidad, o igualmente, para poner de manifiesto un comportamiento resoluto.

El campo conceptual de la 'claridad' en el discurso hablado se apoya, asimismo, en la metáfora cognitiva HABLAR CLARO ES RECORRER UN CAMINO CORTO, como se aprecia en las UF alemanas kurz und bündig [etw. sagen] y en in der Kürze liegt die Würze. La unidad léxica bündig de la UF kurz und bündig [etw. sagen] se corresponde, a su vez, con la metáfora cognitiva HABLAR CLARO ES SUJETAR/UNIR que procede, asimismo, de la archimetáfora EL DISCURSO ES UN TEJIDO.

Para cerrar este apartado, el CAMINO en el campo conceptual de la 'claridad' es además de recto, liso y llano, y por tanto, se activa la metáfora HABLAR CLARO ES SEGUIR UN CAMINO LISO Y LLANO: al. etw. platt sagen, jdm. etw. glatt ins Gesicht sagen, alles glatt gehen, glatte Worte machen; esp. lisa y llanamente, de plano, a la pata la llana, etc. Este tipo de UF se emiten con frecuencia en presencia del interlocutor, cuya imagen puede verse comprometida (Fernández Bernárdez 2005: 129).

\section{Conclusiones}

Como entidad abstracta, la comunicación verbal se presenta como un instrumento que puede aprehenderse a partir de esquemas o parámetros más concretos tomados de la forma de concebir la realidad circundante, la cual descansa en aspectos cognitivos universales del cuerpo humano tales como espacio, tiempo y movimiento. Tomando como punto de referencia los esquemas de imágenes, el esquema centro-periferia evidencia que el campo conceptual de la 'claridad' es céntrico y que se traduce en ambas fraseologías a través del somatónimo Herz/corazón, si bien hemos constatado pequeñas diferencias que se explican por cuestiones culturales, como, por ejemplo, el componente Leber en la UF frisch von der Leber weg reden encuentra correlato en la fraseología española por medio del componente léxico 'víscera' en la colocación hablar visceralmente y en la UF hablar con las vísceras. Por otra parte, el componente médula o meollo no presenta equivalencia fraseológica en alemán a la hora de expresar claridad o sinceridad. Curiosamente, la fraseología alemana asocia los componentes 'hígado' y 'corazón' al concepto de la 'claridad' frente a la española que se ciñe únicamente a los somatónimos 'corazón' o 'pecho'. En cambio, el 'hígado' en la fraseología española hace referencia a las emociones negativas como la ira.

La claridad es, asimismo, comprensible en términos de RECIPIENTE merced, de nuevo, al somatónimo Herz cuya productividad es mayor en alemán que en español. En conexión con el RECIPIENTE, observamos los conceptos de APERTURA/CERRAZÓN a través de unidades léxicas esp. 'rebozo', 'calzón'; al. Visier, Schleier. Y, por último, el esquema del CAMINO nos ayuda a comprender que la 
claridad evidencia un camino recto y liso, imagen que se activa por igual tanto en la fraseología alemana como en la española.

El hecho de que no siempre coincidan los constituyentes léxicos en ambas fraseologías no influye en la forma de conceptualizar la 'claridad' del discurso hablado, sin embargo, estas diferencias ponen de relieve las particularidades culturales intrínsecas a cada comunidad lingüística. En general, se registran paralelismos en las archimetáforas, si bien algunas imágenes concretas que subyacen a las UF no siempre coinciden en ambos sistemas lingüísticos, lo cual se refleja en determinadas diferencias léxicas, pero fundamentalmente se trata de la misma metáfora.

\section{Referencias bibliográficas}

AzNÁReZ Mauleón, M., La fraseología metalingüistica con verbos de lengua en español actual. Frankfurt am Main: Peter Lang 2006.

Baldauf, C., Metapher und Kognition. Grundlage einer neuen Theorie der Alltagsmetapher. Frankfurt am Main: Peter Lang 1997.

Baranov, A. / DOBROVOL' SKIJ, D., «Kognitive Modellierung in der Phraseologie: zum Problem der aktuellen Bedeutung», Beiträge zur Erforschung der deutschen Sprache 10 (1991), 112-123.

FerNÁNDEZ BERNÁRDEZ, C., «Fraseología metalingüística con decir. Análisis de algunas unidades que expresan acuerdo intensificado», en: CASAdo Velarde, M. / GonZÁlezz Ruiz, R. / LoUReda LAMAS, Ó. (eds.), Estudios sobre lo metalingüistico (en español). Frankfurt am Main: Peter Lang 2005, 119-145.

GECK, S., Actividad intelectual y emociones. Dos modelos cognitivos metafóricos en alemán y español. Valladolid: Secretariado de Publicaciones e Intercambio Editorial 2003.

Herrero KACZMAREK, C., «O encontro e o desencontro expresado a través dos fraseoloxismos do campo cognitivo FALAR», Cadernos de Fraseoloxía Galega 13 (2011), 177-190.

JÄCKEL, O., Wie Metaphern Wissen schaffen: Die kognitive Metapherntheorie und ihre Anwendung in Modell-Analysen der Diskursbereiche Geistestätigkeit, Wirtschaft, Wissenschaft und Religion. Hamburgo: Dr. Kovac 2003.

Johnson, M., The body in the Mind. Chicago: Chicago University Press 1987.

Johnson, M., El cuerpo en la mente. Trad. H. González Trejo. Madrid: Debate 1991.

Lakoff, G. / Johnson, M., Metáforas de la vida cotidiana. Trad. de C. González Marín. Madrid: Cátedra 1986.

Lakoff, G., Women, Fire and Dangerous Things. What Categories Reveal about the Mind. Chicago: The University of Chicago Press 1987.

LAKOFF, G., «Some empirical results about the nature of concepts». Mind \& Language 4, 1 y 2 (1989), 103-129.

Luque Durán, J. De D., Aspectos universales y particulares del léxico de las lenguas del mundo. Estudios de Lingüística del Español. Granada: Impredisur 2004.

MANSILLA, A., «Lying as metaphor in a bilingual phraseological corpus (German-Spanish) », en: Taboada, M. / Doval, S. / González, E. (eds.), Contrastive Discourse Analysis. Functional and Corpus Perspectives. Sheffield: Equinox Publishing Ltd. 2013, 327-344.

Mellado Blanco, C., «La metáfora en la formación de fraseologismos alemanes y españoles: las metáforas locales», Paremia 8 (1999), 333-338.

Montoro del Arco, E. T., «La fraseología del vino». Per Abbat. Boletín filológico de actualización académica y didáctica II (2007), 131-136. 
Olza Moreno, I., «Metáfora y conocimiento del lenguaje: fraseología metalingüística en español y francés actuales», en: GonzÁlez Ruiz, R. / CASAdo Velarde, M. / Esparza TORres, M. A. (eds.), Discurso, lengua y metalenguaje. Balance y perspectivas. Hamburgo: Buske 2006, 155-174.

RigotTI, F., «Schleier und Fluß - Metaphern des Vergessens», en: BuchHolz, M. B. (ed.), Metaphernanalyse. Göttingen: Vandenhoeck und Ruprecht 1993, 229-253.

RoBles i SABATER, F., «Aproximación a la fraseología metalingüística del alemán. Las locuciones verbales con reden, sagen y sprechen», Anglogermánica Online (2005), 43-64.

Roos, E., Idiom und Idiomatik. Ein sprachliches Phänomen im Lichte der Kognitiven Linguistik und Gestalttheorie. Aquisgrán: Shaker 2001.

Santos Domínquez, L. A. / EsPinosa Elorza, R., Manual de semántica histórica. Madrid: Síntesis 1996.

Schemann, H. / Mellado Blanco, C. / Buján, P. / Iglesias, N. / Larreta, J. P. / MansiLLA, A., Idiomatik Deutsch-Spanisch. Hamburgo: Buske 2013.

Ungerer, F. / Schmid, H. J., An Introduction to Cognitive Linguistics. Londres/Nueva York: Longman 1996. 